\title{
Comparison of nondestructive testing: Infrared thermography, electrical resisitivity and capacity methods for assessing a reinforced concrete structure
}

Received (in revised form): 2nd March, 2007

\section{Colette Sirieix}

is a doctor of science. She first worked in BRGM and ANTEA companies, and became an associate professor at Bordeaux 1 University (CDGA, France) in 1997. She is a specialist in geophysics: infrared thermography and electrical resistivity methods. Her research deals especially with the characterisation of rocks and concrete damage. She is a member of RGCU, SENSO French programmes and EAGE.

\section{Jean François Lataste}

is associate professor in University Bordeaux 1, after obtaining a PhD dealing with the assessment of electrical resistivity on concrete structures. His works in the laboratory CDGA (now becoming GHYMAC) are on material electrical properties, on the building materials and applied geology fields. He participates in the RILEM TC INR.

\section{Denys Breysse}

has carried out research works that are mainly focused on the consequences of heterogeneities in soils and building materials on the assessment of the construction properties and reliability. Fields of application are in soil-structure interaction, maintenance and management of technical assets and in nondestructive assessment of concrete. Presently, he is the chairman of RILEM TC INR-207 on combination of nondestructive techniques for assessment of concrete. He is also President of the French Association of Universitarian Research (AUGC).

\section{Samuel Naar}

has made his master speciality geophysics at Rennes University. His PhD was on infrared thermography and electrical resistivity techniques, for nondestructive testing of concrete structures. He has prepared it with the University Bordeaux 1 (CDGA) in France, and with Sherbrooke University (Département de Génie Civil) in Quebec. He has been working for a few months for the company Concrete, dealing with structure damage assessment and rehabilitation.

\section{Xavier Dérobert}

is a senior scientist at LCPC (FR), and has been a specialist in ground-penetrating radar (GPR) for over 15 years in civil engineering. He received an Engineer of State Public Works diploma in 1987, a PhD in electromagnetism in 1995 and a 'Leading Research Ability' diploma in 2003. He is the author of more than 50 publications/communications in the NDT field and organised two national conferences on GPR in 2001 and 2003.

Correspondence: Colette Sirieix, CDGA Université Bordeaux 1, Avenue des Facultés, 33405 Talence cedex, France; Tel: +33540 0087 97; Fax: +335400031 13; E-mail: c.sirieix@cdga.u-bordeaux1.fr

\begin{abstract}
A series of investigations were carried out on a precast concrete duct in Tarbes, France, which displayed damage patterns. The aim of the study was to rank 55 similar pipe segments in order to determine severity of the damage. The methods used were electrical resistivity measurement, passive infrared thermography and the capacitor method. The first step was to clarify the accuracy of the site measurements of the various techniques in a real situation. All methods allowed water content rate variations and cracks to be distinguished on the surface of concrete. Statistical analysis of the data helped
\end{abstract}


the interpretation of measurements to develop a hypothesis. This original work, analysing several nondestructive test techniques, then combining results, led to establishing a link between damage and moisture. The experimental results have been used to try to quantify the value of the surface moisture. This appears to be the most important physical factor influencing measurements as well as being a way to assess damage.

Journal of Building Appraisal (2007) 3, 77-88. doi:10.1057/palgrave.jba.2950065

\section{Keywords:}

nondestructive testing, moisture, crack, infrared thermography, electrical resistivity, capacitor technique, concrete

\section{INTRODUCTION}

Many civil engineering structures in France, as in all developed countries, reach an age where repairs are necessary. For safety reasons, as well as for increasing the service life and saving natural resources, the development of survey programmes for asset management is essential (Breysse and Abraham, 2005). The survey programmes could help to identify the relevant time and decrease the cost of repair. The development of nondestructive techniques (NDT) applied to civil engineering structures offers new opportunities. Regarding the condition of concrete structures, the quality of the concrete cover has a direct influence on most of the damage processes affecting reinforced concrete structures (carbonation, corrosion, delamination, frost resistance etc).

This paper describes part of the work performed within the research network 'Damage evaluation of concrete cover \& help for diagnosis and repair of civil engineering structures' supported by the RGC\&U (Ministry of Research and Ministry of Public Works). A combination of several methods for testing the concrete cover is the basis of this project (Breysse and Arliguie, 2004). The whole programme combines laboratory tests and on-site investigations (case studies). In the case study described in this paper, five NDTs were performed in situ, but only three resulted in relevant conclusions being able to be drawn from the results.

\section{FIELD EXPERIMENTS: DESCRIPTION OF THE PRECAST DUCT AND TESTING PROCEDURE}

The investigations were carried out on a precast reinforced concrete duct (Figure 1) below the A64 highway near Tarbes in Hautes-Pyrénées, France, which showed visible damage of the surface of the concrete.

The structure is $165 \mathrm{~m}$ long and consists of 55 pipe segments each $3 \mathrm{~m}$ long and is oriented NE-SW in the direction of flow. Reference to the location within the pipe is given by the distance from the NE edge of works $(0-165 \mathrm{~m})$ or by the number of pipe segments from the NE end (1-55). Each pipe section is roughly ovoid in shape with a height of $1.7 \mathrm{~m}$ and a width of $1.8 \mathrm{~m}$ and the concrete thickness is about $20 \mathrm{~cm}$. Only the internal surface of the duct could be inspected and showed some damage, such as cracks, which sometimes contained calcite (Figure 2) and which were mainly to the upper part of the duct.

Based on a visual inspection, the damage pattern recorded was displayed on a diagram prepared by GETEC, a company specialised in nondestructive assessment and repair (Figure 3). Three segments of the duct (21-23) between 60 and $69 \mathrm{~m}$ from the NE end had been repaired in the previous year by shotcreting and accordingly these segments were excluded from the investigation. 


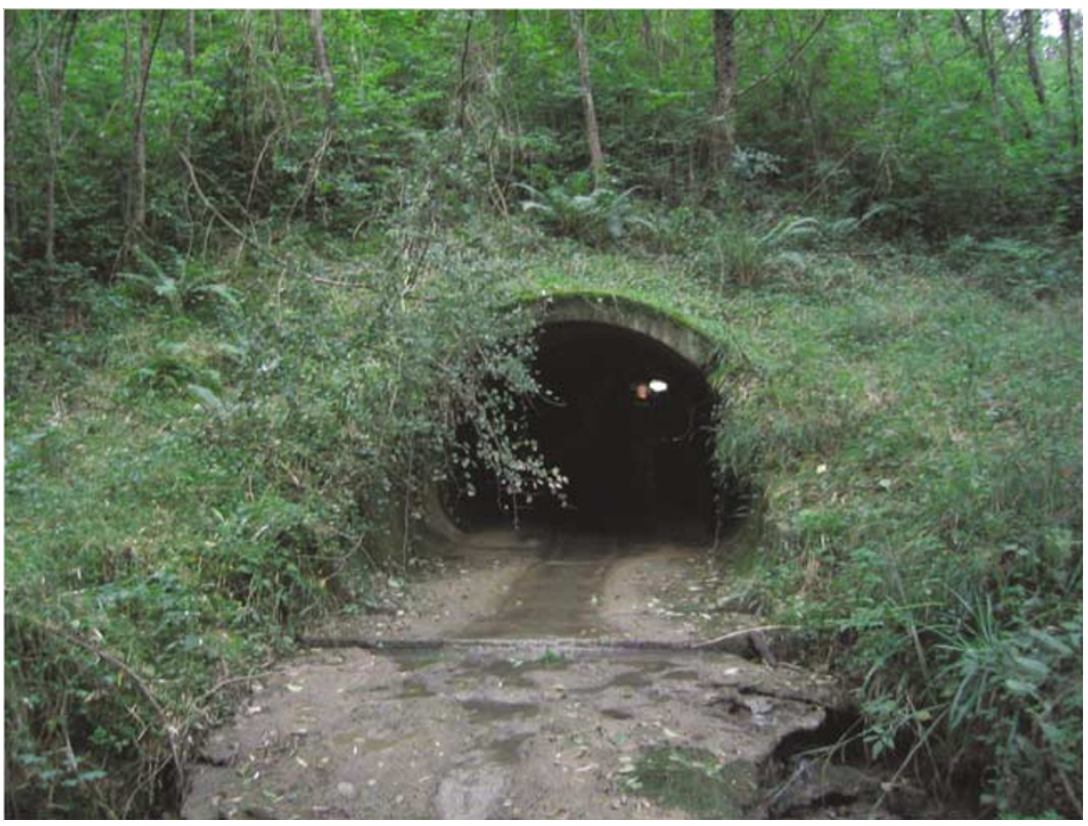

Figure I: $S W$ entrance of the duct $(x=0 \mathrm{~m})$

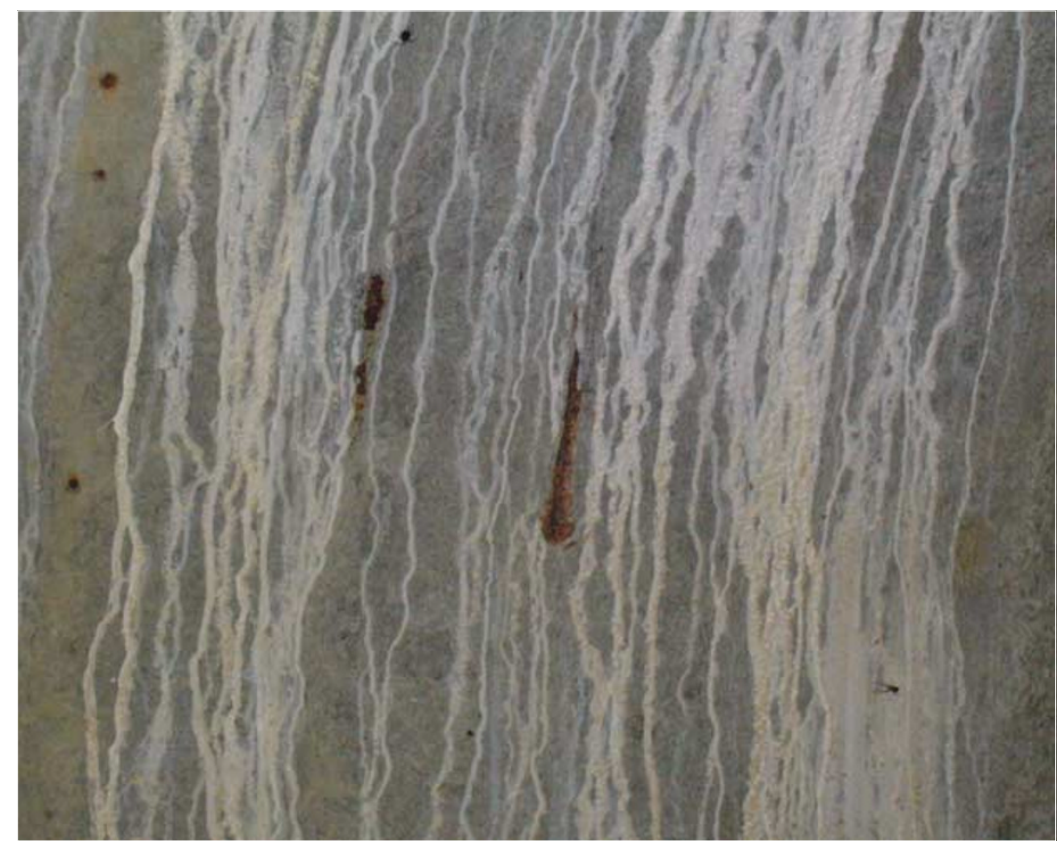

Figure 2: Calcite in cracks and visible corroded rebars

The overall dimensions of the cracks have been evaluated for each 3-m-length segment using the same method that is common in rocks mechanics (Gervais et al., 1993). The cracks appear to be more developed in the middle part of the duct than at its ends (Figure 4). 
状 Sirieix et al
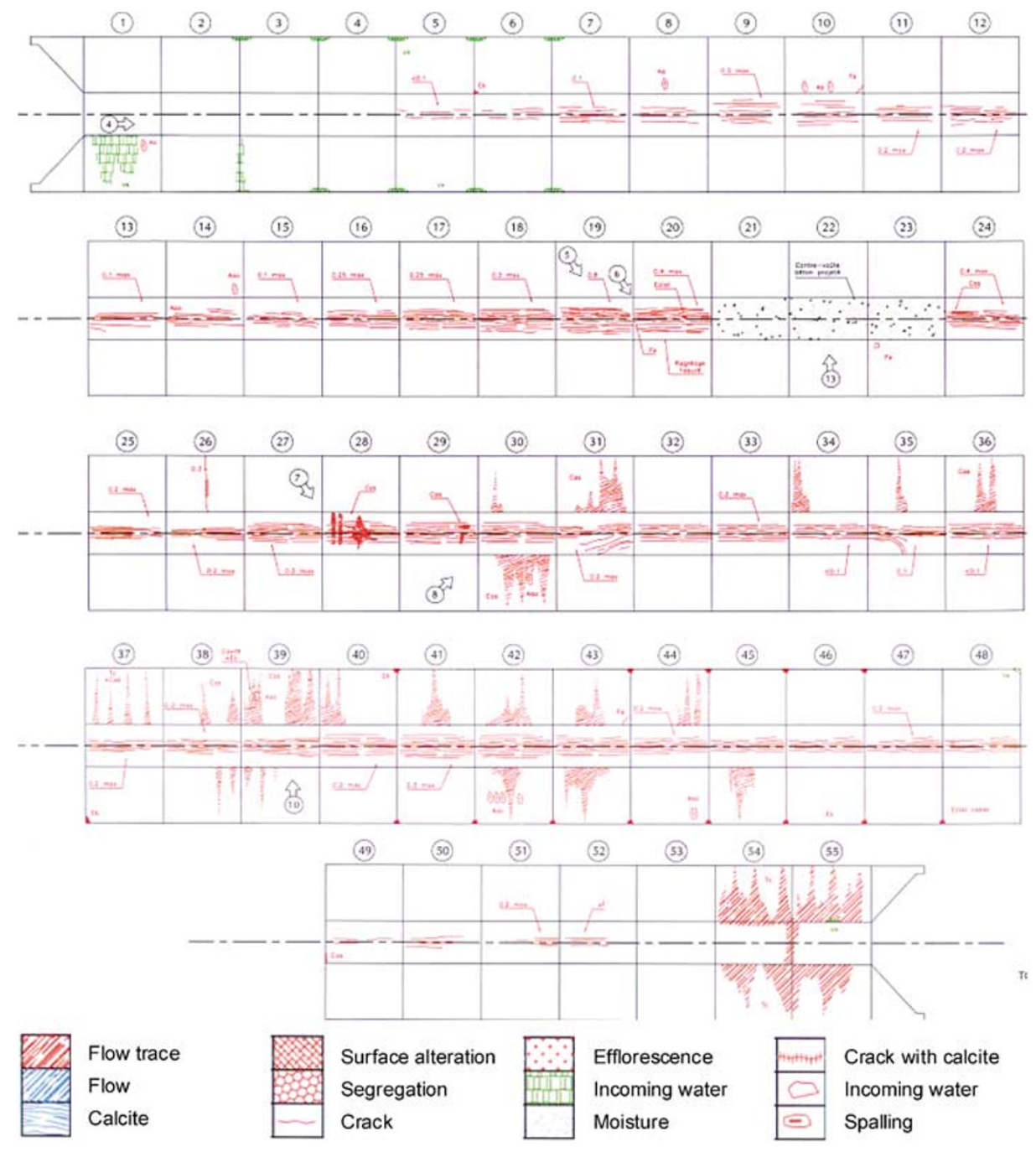

Figure 3: Map of alteration based on a visual inspection of the pipe by the GETEC company (May 2002). Each pipe section measures $3 \mathrm{~m}$ in length

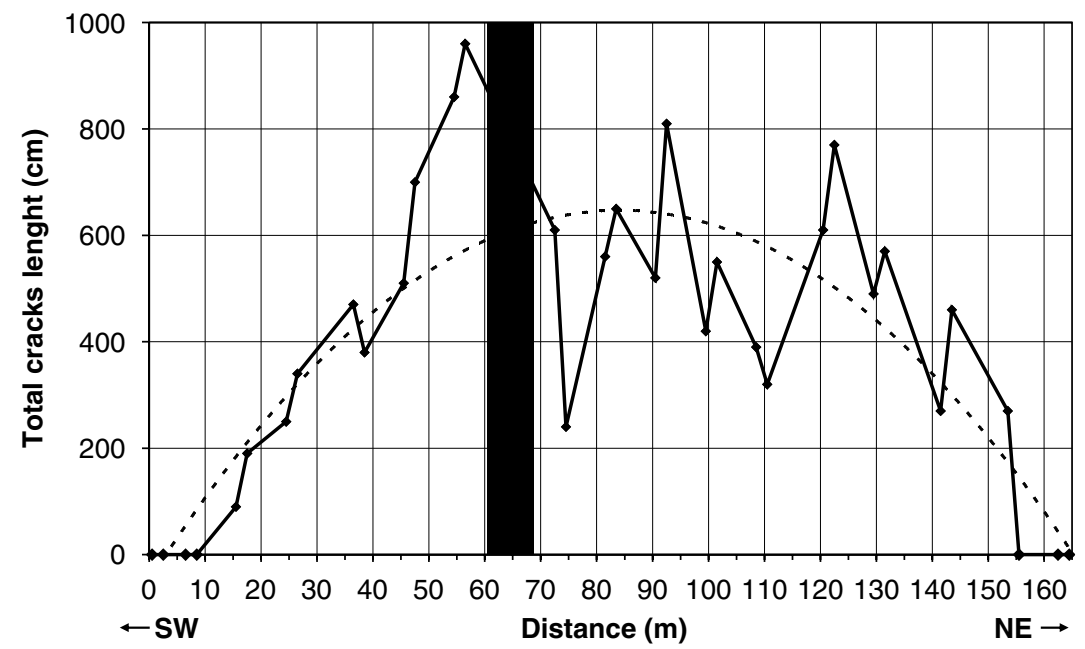

Figure 4: Profile of total cracks length for each segment 


\section{METHODS AND MEASUREMENTS}

Measurements have been carried on the upper part of 17 pipe segments (which corresponds to one segment out of three). The five NDT methods used were:

1. the capacitor method;

2. electrical resistivity measurements;

3. passive infrared thermography;

4. the radar technique and

5. the ultrasonic surface wave method.

The high density of reinforcement in the concrete prevented the efficient use of radar measurements for this structure. Moreover, due to the curvature and roughness of the surface, the ultrasonic surface wave method was not successfully applied in this case.

\section{Electrical resistivity method}

Electrical resistivity of concrete is mainly affected by the electrolytic conductivity through the porosity of material, which is affected by the quality of the concrete. When operated in a static mode (electrodes in contact with the structure under investigation), the resistivity tomography leads to excellent estimates of the concrete thickness over the rebars. With special attention, each individual rod can be mapped. The resistivity of the concrete alone can be indicative of the integrity (and residual compressive strength) of a concrete structure. Damaged areas and cracks in concrete can act as preferential routes for fluid flow. Mapping of the electrical resistivity distribution will help in diagnosis of defects in concrete structures. A special device has been developed (Figure 5; Lataste, 2002) to measure the concrete cover. The four probes deliver an electrical current between the two lateral probes and measure the potential difference between the other two probes. The apparent resistivity is calculated and can be exploited by drawing electrical resistivity profiles.

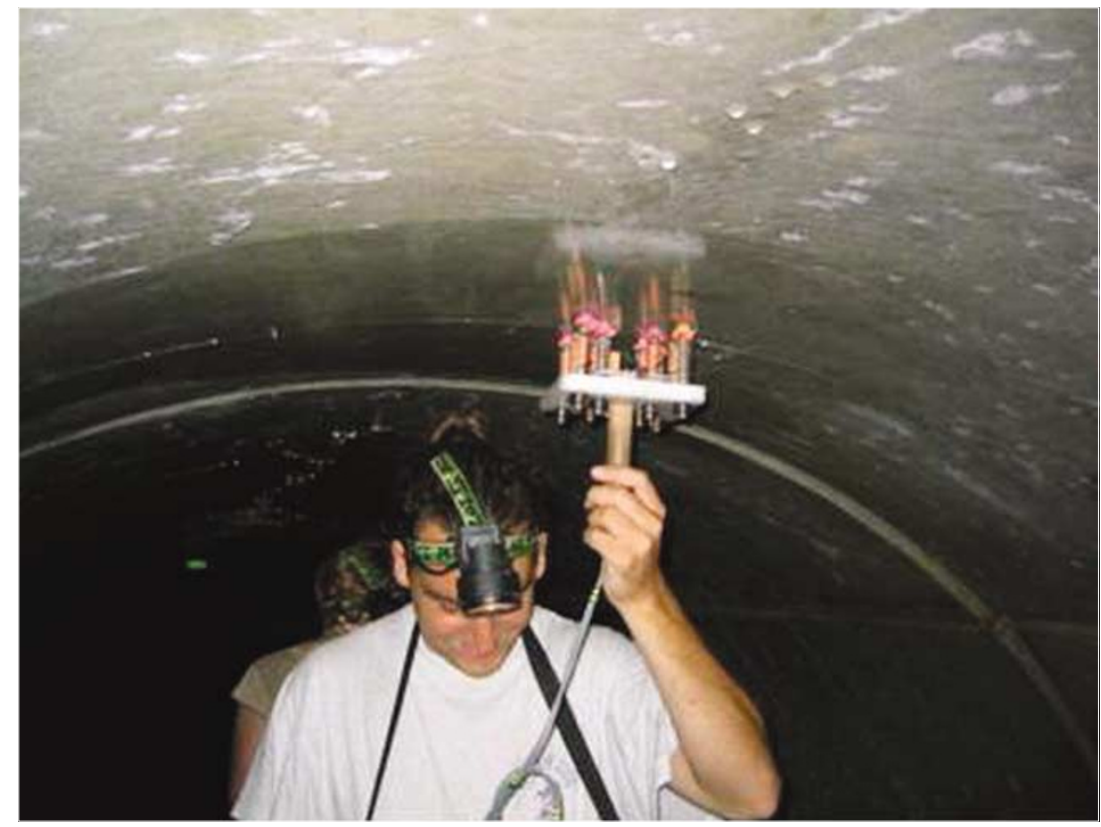

Figure 5: Electrical resistivity measurements 
Each electrical resistivity value is the average value of three measurements at three locations on the same segment in a direction parallel to the axis of the duct. Locations were determined to minimise the influence of rebars which have been detected previously. Three measurements were taken to reduce the statistical uncertainty on resistivity assessment through the assumption of a 'homogeneous condition' for each segment. Measurements were conducted in September 2005 and took about four hours.

\section{Infrared thermography method}

Infrared thermography is a very attractive technique as a new application to civil engineering structures as it is a noncontact, time-saving and cost-saving method. Furthermore, the equipment is often small and practical to use (Figure 6). This technique provides thermal images that represent the spatial distribution of the thermal radiation of the surface of the concrete (apparent surface temperature). To analyse results, it is necessary to combine thermal images with visual images.

The temperature value given in the results is the average temperature of the concrete surface (where there was no surface debris). The distance between the camera (FLIR SC2000, standard objective) and the concrete surface was $120 \mathrm{~cm}$, which gave image sizes of $38 \times 46 \mathrm{~cm}^{2}$. It was not possible to distinguish the cracks directly on thermal images because of the instantaneous field of view of the camera $(1.3 \mathrm{mrad}$, which corresponds to a $1.56 \mathrm{~mm}$ crack width at a $120 \mathrm{~cm}$ distance). The surface temperature of the concrete is directly linked to emissivity, thermal diffusivity and evaporation of the concrete (Sirieix

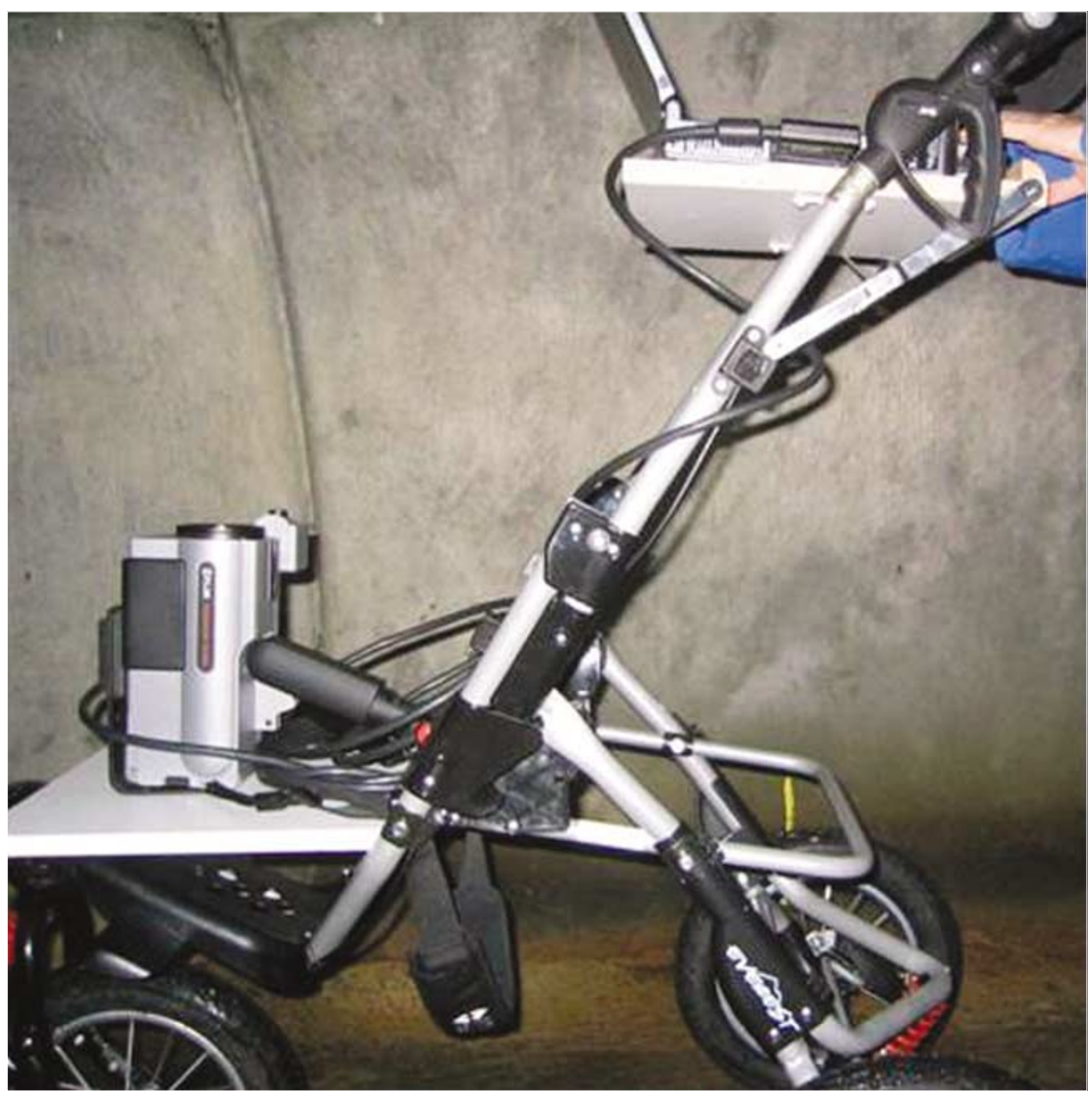

Figure 6: Infrared thermography measurement device 
et al., 2005). In this kind of work (tunnel), there is no reflection, no solar radiation nor any artificial source of heat and the emissivity will be constant and high (more than 0.93). Therefore in this case, where the problem involves nonsteady-state heat conduction, a variation of surface temperature would be dependent on thermal diffusivity or evaporation. Measurements were conducted in September 2005 and took only one hour.

\section{Capacitor method}

The capacitor method was mainly developed for measuring the moisture content of structural concrete, by the Laboratoire Central des Ponts et Chaussées (Baron and Tran, 1977; Blaszczyk et al., 1993). The principle is to obtain the change in dielectric properties of concrete between two electrodes from the resonant frequency of an oscillating circuit. The electrodes are two parallel metallic plates laid on the concrete (Klysz et al., 2003). These electrodes form a capacitor with the concrete, the capacitance of which is dependent on the geometry of the electrodes $\left(7 \times 10 \mathrm{~mm}^{2}\right.$, see Figure 7$)$ and on the dielectric constant of the concrete. Thus, the resonant frequency depends on the concrete's properties. These measurements have been shown to be very sensitive to the concrete moisture content (Derobert et al., 2005).

Each value is the difference between one measurement (taken on the keystone of the duct section) and a reference value taken in open air (without concrete between the electrodes) for the same geometry. Measurements were conducted in June 2005 and took four hours.

\section{RESULTS}

The combined results are shown for each of the three test methods in Figures 8-10. They show a similar trend of the data along the duct in that they are quite constant in the central sections (between approximately 40 and $130 \mathrm{~m}$ ) and show an increase at either end,

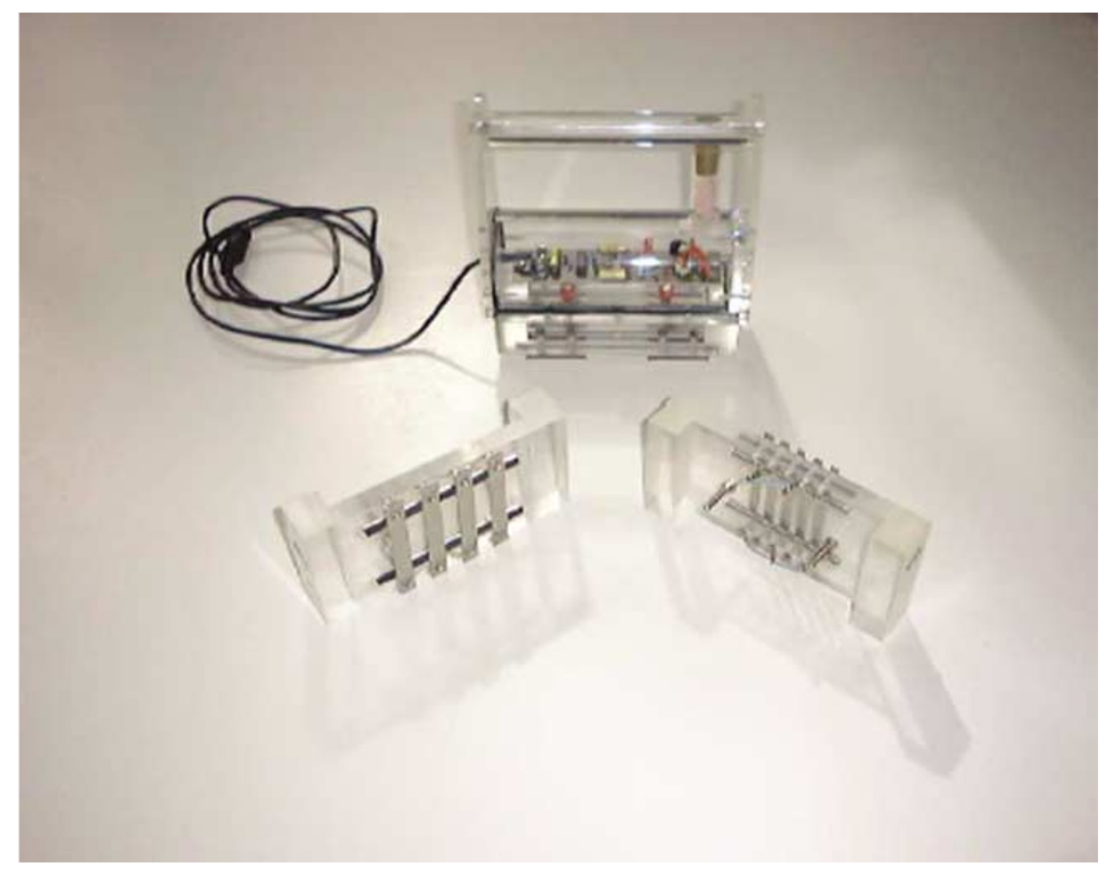

Figure 7: Capacitor apparatus (Photo courtesy of X.Dérobert) 
although the increase was not symmetrical, being lower at the North-East end. In the same way, it can be seen that the damage pattern exhibits (Figure 4) more cracks between 40 and $130 \mathrm{~m}$ than at the ends (RGCU - Final report, 2005). On the three graphs

(Figures 8-10), the dotted curved line simply comes from a second-order polynomial regression on the experimental data. Its only merit is to highlight the gross trend but it does not provide any explanation.

\section{DISCUSSION}

Figures 8-10 suggest a correlation between the results provided by the three techniques, since all three patterns show a similar trend, despite the local (error bars for each average value) and global variations.

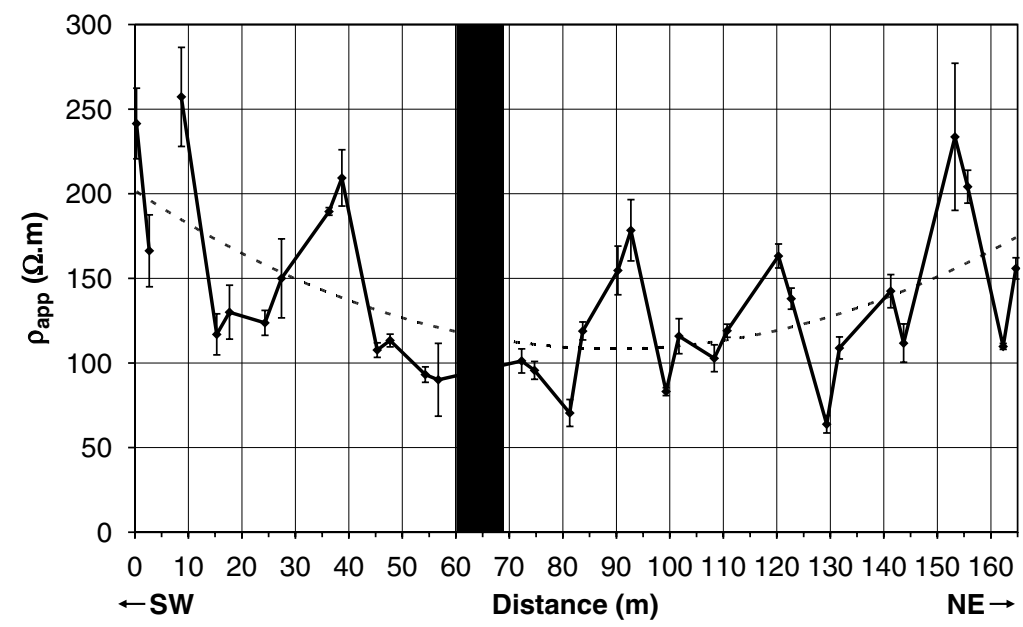

Figure 8: Average values and error bars of electrical resistivity measured in three points, along the keystone of the duct

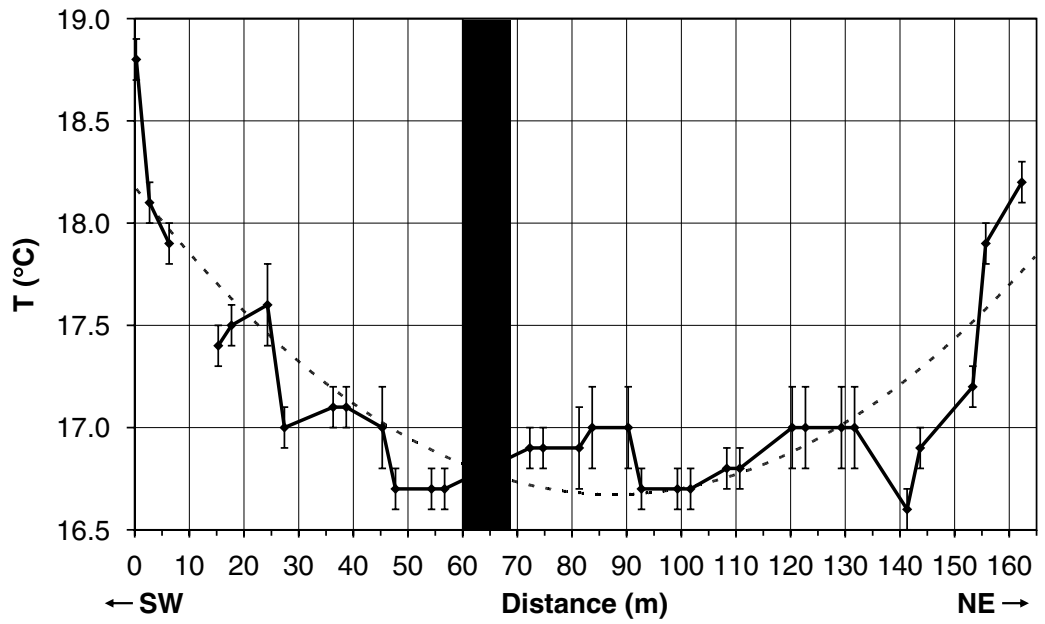

Figure 9: Average values and error bars of the surface temperature of the keystone as measured by thermal imaging. Each image was $38 \times 46 \mathrm{~cm}^{2}$ 


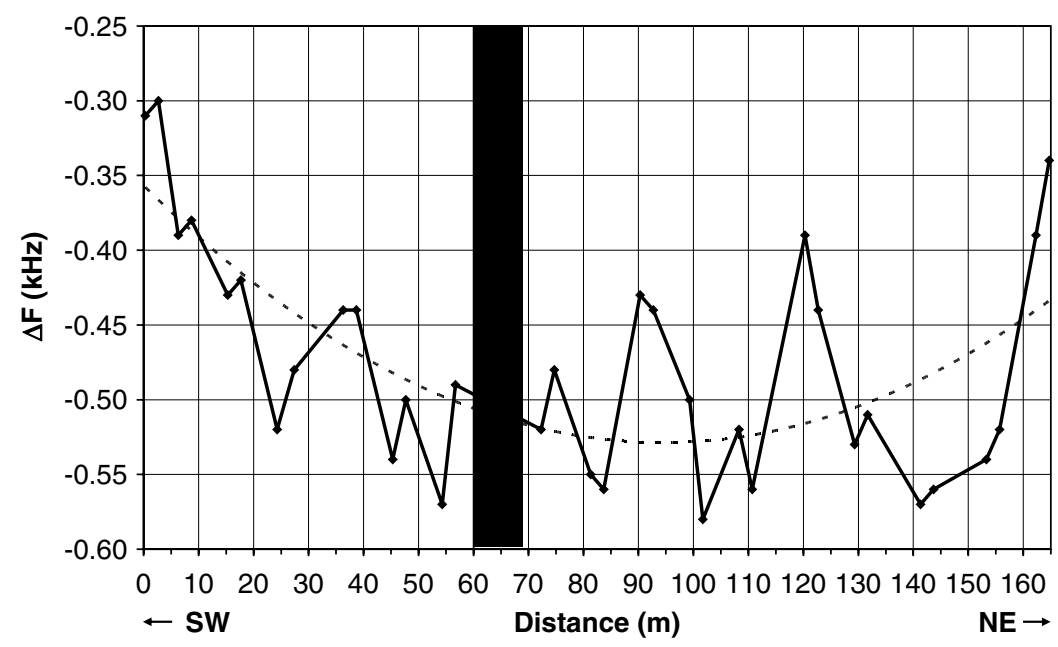

Figure 10: Difference in frequency as measured by the capacitor method

To check the significance of these correlations, statistical analysis of the series was performed to test the independence of the variables with $C$ (difference of frequency in $\mathrm{kHz}$ ), $T$ (thermal image temperature in ${ }^{\circ} \mathrm{C}$ ) and $R$ (apparent resistivity in $\Omega \mathrm{m}$ ). Assuming a linear model for each pair of variables $(R / T, C / R, C / T)$, the null hypothesis $\mathrm{H}_{0}$ (independence of the variables) must be rejected. The test is highly significant when testing $\mathrm{H}_{0}$ for $(R / T)$ and $(C / R)$ and very highly significant for $(C / T)$. Coefficients of correlation $R$ are respectively $0.52,0.49$ and 0.69 (two outliers' values (outliers are high and low values that fall out of the range of typical values and are calculated statistically) have been deleted in each series). Since the null hypothesis is rejected at least at a high significance level, we infer that the parameters $R, T$ and $C$ are correlated.

To interpret these results, it is necessary to know:

- what chemical or physical process can be involved in the damage development and

- how the parameters linked with these processes can influence the three different physical properties measured here: electrical resistivity, thermal diffusivity and relative permittivity.

The three measurements are known to be temperature dependent, thus it is natural to check the effects of air temperature to assess if it can have a significant influence on what is measured. Owing to the environmental context and the orientation of the duct (NE/SW), the temperature regularly decreases from 17 to $13^{\circ} \mathrm{C}$ in September from $x=0$ to $x=165 \mathrm{~m}$. $R, T$ and $C$ measurements increase at both ends and their profiles are roughly parabolic. Based on the measured air temperature variation $\left(4^{\circ} \mathrm{C}\right)$, variation in resistivity is estimated at about 5 per cent (Whittington et al., 1981), which is much less than the measured spatial variations.

Another explanation could be differences in the original concrete properties along the duct. The duct was, however, made of precast concrete so that all the pipes are theoretically identical (in geometry, composition and in physical properties). Therefore, there is no explanation for the variation in properties of the concrete in the central part of the duct from the building process. 
The third parameter that could influence the measurements is crack density. Thus, additional statistical analyses have been performed to assess the correlation between $R, T$ and $C$ and a fourth parameter, $F$, the cumulative crack length. Assuming a linear model for each pair of variables $(C / F, T / F$ and $R / F)$, the null hypothesis $\mathrm{H}_{0}$ (independence of the variables) must be rejected. The test is highly significant when testing $\mathrm{H}_{0}$ for $(C / F)$ and $(R / F)$ and very highly significant for $(T / F)$. Coefficients of correlation $R$ are, respectively, $0.39,0.74$ and 0.37 for $C / F, T / F$ and $R / F$. Since the null hypothesis is rejected at least at a high significance level, we can infer that the parameters $C, T$ and $R$ are related to the cumulative crack length at the segment scale.

It should be noted that the apparent surface temperature was more correlated with the cumulative crack length than with the two other measurements. Thermal diffusivity is very sensitive to discontinuities, thus this physical relation can explain this good correlation. The study of electrical resistivity has also shown that it is influenced by discontinuities (Lataste et al., 2003). The measurement noise during resistivity measurement is, however, higher than that during temperature measurements, which might explain the lower correlation coefficients.

The analysis of capacity measurements highlights a problem since this technique seems not to be sensitive to cracking but mainly to water content (RGCU, final report, 2005). The experimental study of concrete specimens of $25 \mathrm{MPa}(\mathrm{B} 25$, porosity 0.179 ) has shown a linear relationship between saturation and the frequency of capacity:

$$
f=5.13-0.35 \mathrm{Sr}
$$

where $f$ is the frequency and $\mathrm{Sr}$ the saturation rate (Breysse et al., 2006). The coefficient of correlation $R$ is 0.93 and the null hypothesis $\mathrm{H}_{0}$ (independence of the variables) must be rejected. The test is very highly significant when testing $\mathrm{H}_{0}$. It is therefore natural to think that the water content (or saturation rate) can be a common explanation for explaining all the observed trends.

With regard to testing using the electrical method on the same concrete as above, a power relationship can be drawn between electrical resistivity and saturation, this relationship having the same shape and the same physical basis as Archie's law (Archie, 1942; Archie's law relates the electrical conductivity of sedimentary rocks to its porosity and brine saturation) for rocks and other porous materials:

$$
\rho=0.028 \mathrm{Sr}^{-2.43}
$$

where $\rho$ is electrical resistivity and $\mathrm{Sr}$ the water saturation (Naar, 2006). The coefficient of correlation $R$ is -0.99 and the null hypothesis $\mathrm{H}_{0}$ (independence of the variables) must be rejected. The test is very highly significant when testing $\mathrm{H}_{0}$.

While these specimens were not investigated with infrared thermography, thermal conductivity (Missenard 1965; Santos, 2003) and thermal diffusivity (Poblete and Acebes Pascual, 2007) are known to be dependent on the moisture content.

The three parameters $C, R$ and $T$ are statistically dependent. The most important physical parameter that can explain and justify these correlations and the similarity of longitudinal trends along the duct seems to be the water content of the concrete. The 
question remains to explain their correlation with crack length and two alternative explanations can be proposed:

- a high level of saturation rate favours damage and cracking of concrete; thus, cracks are more frequent and longer where the water content is high. Since NDTs are sensitive to water content, they reveal the existence of damage and cracking;

- for other reasons (the more probable are stresses caused by the weight of soil surrounding the duct since the duct passes below a motorway at the base of an embankment whose height is more than $10 \mathrm{~m}$ ), damage develops in concrete and results in cracks. Moisture in the embankment reaches these cracks and is measured via NDT.

Thus NDT reveals the damage through the measurement of the water content of cracks.

The second explanation seems to be more relevant, since it accounts for the environmental context of this duct and is compatible with all the observed measurements. In any case, the experimental on-site measurements confirm their sensitivity to damage and cracking, which is interesting for helping the manager in his decision process regarding maintenance and repair of the structure.

\section{CONCLUSION}

These in situ measurements show that the three methods can provide quantitative information about the water content in the surface of concrete. This parameter is of high interest since an important (spatial or temporal) variation of moisture content can reveal damage (alkali-reaction with more water, mechanical damage and cracks, freeze and thaw, leaching etc). The relative interest of each of these three methods depends on their accuracy (among others via the signal to noise ratio, visible in Figures 8-10) and on their ease of use. For instance, infrared thermography can provide quickly a first set of 'general' measurements, which then enable the user to deepen their investigations in specific areas of potential interest.

Moreover, if it was possible to determine more precisely the influence of water content on the values of the measured parameters, we would be able, in some cases, to correct the effect of the 'natural' gradient of moisture in a structure, and to check if the remaining signal was constant or not. Laboratory tests, not detailed in this paper, have enabled the influence of water content for electrical and capacitor methods for a given concrete to be quantified (RGCU - Final report, 2005). The development of such relationships for infrared thermography would also be very interesting since it is the fastest method.

Another difficulty comes from the fact that the various measurements depend on several material parameters (cracking, porosity and water content being the more important). In this case, infrared thermography seems to be more correlated with cracks than with the other two methods. The challenge is to be able to uncouple the effects of these various influencing factors, such as to quantify each of them. This task is now undertaken in a RILEM Technical Committee (TC-INR - 207) and in a National Research Programme (ANR-SENSO) whose purpose is to develop a representative database for various concrete mixes, various potential influent parameters and a large number of NDT methods.

\section{Acknowledgements}

The authors gratefully acknowledge 'Réseau Génie Civil \& Urbain', the Ministry of Public Works and Ministry of Research of French Government for their financial support. 


\section{References}

Archie, G. (1942) 'The electrical resistivity log as an aid in determining some reservoir characteristics', Transactions of the American Institute of Mining and Metallurgical Engineers, 146, 54-62.

Baron, J.-P. and Tran, N.-L. (1977) Méthodes de mesure et de contrôle des teneurs en eau de matériaux dans les LPC. Bulletin des Laboratoires des Ponts et Chaussées, no. 87, pp. 85-96 (janvier-février 1977).

Blaszczyk, F., Blaszczyk, R., Trochet, B., Bigorre, M. and Dupas, A. (1993) Mesure de la teneur en eau en continu d'un matériau granulaire: TRITON II. Mesure à la jetée d'un transporteur, Bulletin des Laboratoires des Ponts et Chaussées, no. 186, pp. 85-87 (Juillet-Août 1993).

Breysse, D. and Abraham, O. (2005) Méthodologie d'évaluation non destructive de l'état d'altération des ouvrages en béton, Presses de l'École Nationales des Ponts et Chaussées, Paris.

Breysse, D. and Arliguie, G. (2004) Couplage de méthodes d'END pour évaluer l'altération du béton armé des ouvrages. Colloque 'Diagnobéton 2004', Sherbrooke, Canada, Québec, November 2004.

Breysse, D., Sirieix, C., Balayssac, J.P. and Lataste, J.F. (2006), Interest of coupling several Non Destructive Techniques for diagnosis of concrete structures Structural Faults and Repairs, Edtor MC Forde, p. 8.

Derobert, X., Balayssac, J.P. and Laguerre, L. (2005) 'Chapitre B4: Méthodes électromagnétiques d'évaluation non destructive in Breysse, D. and Abraham, O. (eds.) Méthodologie d'évaluation non destructive de l'état d'altération des ouvrages en béton, Presses de l'École Nationales des Ponts et Chaussées, Paris, pp. 235-252, (555pp., ISBN 2-85978-405-5).

Gervais, F., Riss, J. and Gentier, S. (1993) Caractérisation stéréologique de la géométrie d'un massif rocheux fracturé : application aux carrières de Comblanchien (Côte d'Or, France). Bulletin de la société Géologique de France, t. 164 , no. 3, pp. 459-471.

Klysz, G., Balayssac, J.P., Derobert, X. and Aubagnac, C. (2003) Evaluation of cover concrete by coupling some non-destructive techniques - Contribution of in-situ measurements. Non-Destructive Testing in Civil Engineering (NDT-CE), Berlin, Allemagne, poster no. 009 (September 2003).

Lataste, J.-F. (2002) Évaluation Non Destructive de l'état d'endommagement des ouvrages en béton armé par mesures de résistivités électriques. Thèse de doctorat, Université Bordeaux I, 295pp. (décembre 2002).

Lataste, J.-F., Sirieix, C., Breysse, D. and Frappa, M. (2003) 'Electrical resistivity measurement applied to cracking assessment on reinforced concrete structures in civil engineering', NDT\&E International., 36(6), 383-394.

Missenard, A. (1965) Conductivité thermique des solides, liquides, gaz et de leurs mélanges, Ed. Eyrolles, Paris, p. 554.

Naar, S. (2006) Évaluation Non Destructive du béton par mesures de résistivité électrique du béton par mesures de résistivité électrique et thermographie infrarouge passive. Thèse de doctorat, Université Bordeaux I et Université de Sherbrooke, 248pp. (mai 2005).

Poblete, A. and Acebes Pascual, M. (2007) 'Thermographic measurement of the effect of humidity in mortar porosity', Infrared Physics \& Technology, 49, 224-227.

RGCU Final report (2005), Evaluation de la dégradation du béton d'enrobage et aide au diagnostic et à la réparation des ouvrages, 207pp. (mars 2005).

dos Santos, W.N. (2003) 'Effect of moisture and porosity on the thermal properties of a conventional refractory concrete', Journal of the European Ceramic Society, 23, 745-755.

Sirieix, C., Defer, D. and Antczak, E. (2005) 'Chapitre B5: Méthodes thermiques d'évaluation non destructive in Breysse, D. and Abraham, O. (eds.) Méthodologie d'évaluation non destructive de l'état d'altération des ouvrages en béton, Presses de l'École Nationales des Ponts et Chaussées, Paris, pp. 253-274 (555pp.).

Whittington, H.W., McCarter, J. and Forde, M.C. (1981) 'The conduction of electricity through concrete', Magazine of Concrete Research, 33(144), 48-60. 